Review - Biological and Applied Sciences

\title{
Microalgae: Cultivation Aspects and Bioactive Compounds
}

\author{
Diego de Freitas Coêlho ${ }^{{ }^{\star}}$ \\ https://orcid.org/0000-0002-2123-5891 \\ Louise Lacalendola Tundisi ${ }^{2}$ \\ https://orcid.org/0000-0002-3374-6103 \\ Keilla Santos Cerqueira ${ }^{3}$ \\ https://orcid.org/0000-0002-1308-0754 \\ Jacqueline Rego da Silva Rodrigues ${ }^{3}$ \\ https://orcid.org/0000-0003-4033-5254 \\ Priscila Gava Mazzola ${ }^{2}$ \\ https://orcid.org/0000-0002-3795-8189 \\ Elias Basile Tambourgi ${ }^{1}$ \\ https://orcid.org/0000-0003-3275-0810
}

Roberto Rodrigues de Souza ${ }^{3}$

https://orcid.org/0000-0001-8919-2675

${ }^{1}$ University of Campinas, Faculty of Chemical Engineering, Cidade Universitária Zeferino Vaz, Campinas, SP, Brazil; ${ }^{2}$ University of Campinas, Faculty of Pharmaceutical Sciences, Cidade Universitária Zeferino Vaz, Campina, SP,Brazil, ${ }^{3}$ Federal University of Sergipe, Chemical Engineering Department, São Cristóvão, SE, Brazil.

Received: 2018.07.05; Accepted: 2019.03.24.

*Correspondence: diegofcoelho@gmail.com; Tel.: +55 1935213908

\section{HIGHLIGHTS}

- Microalgae selection and isolation follow established and well-known microbiological methods;

- Mixotrophic cultivation allows the use of multiple carbon sources as an energy source;

- Agroindustrial and domestic waste can be used to improve biomass production;

- Microalgae can produce biocompounds with anticancer and anti-inflammatory activities. 


\begin{abstract}
Microalgae are aquatic unicellular microorganisms that can be found both in freshwater and marine systems; are capable of photosynthesis; and can grow as individual cells or associated in chains or small colonies. Microalgae cultivation has gained large momentum among researchers in the past decades due to their ability to produce value metabolites, remarkable photosynthetic efficiency, and versatile nature. The wide technological potential, and thus increasing amount of scattered knowledge, may become the very first barrier that a post graduating student, or any non-specialist reader, will face when introduced to the subject. In this review paper, we access the core aspects of microalgae technology, covering their main characteristics, and comprehensively presenting the main features of their various cultivation modes and biological activity from metabolites.
\end{abstract}

Keywords: Microalgae; Microalgae Selection and Isolation; Green Products; Microalgae Cultivation; Bioactive Compounds.

\title{
INTRODUCTION
}

Microalgae, or microphytes, are defined as aquatic unicellular microorganisms that can be both found in freshwater and marine systems [1]; are capable of photosynthesis [2]; and found in many shapes and sizes, ranging from three to ten micrometres [3]. Cyanobacteria, also called blue-green algae, are frequently considered part of the same group due to their physiological characteristics and 'photofermentation' feature [4]. They can grow as individual cells or associated in chains or small colonies [5] and play an important role in aquatic ecosystems due to their photosynthetic capability [6].

While studies related to metabolism of microalgae can be found since the 1960s [7], subsequent projects acknowledged their ability to produce high value metabolites and remarkable photosynthetic efficiency [8], showcasing their wide-range solution potential. Subsequently, several other aspects of the culture, such as the effects of light intensity in cell growth [9] or its safety evaluation when using it as food sources, were assessed [10].

The variety of microalgae species assessed is considerably restricted, compared to the forty thousand which had their names published [11]. Research community has focused on those which had shown high protein content [12], ability to produce carotenoids and fatty acids [8], and several other high value products [12]. The biodiversity of microalgae represents an almost untapped resource. Nearly thirty years ago, before the trend had started, Norton et al. [13] estimated that between 200,000 and several million species existed, compared with about 250,000 species of higher plants.

At the time, microalgal biomass culturing was only considered promising when integrated to systems in which it could simultaneously reduce environmental problems [14]. The commonly obtained photosynthetic yield $\left(15-25 \mathrm{~g} \cdot\right.$ dry-weight $\cdot \mathrm{m}^{-2} \cdot$ day $\left.^{-1}\right)$ was considered prohibitive due to the amount of land, energy and nutrients required.

However, successive oil crises coupled with the well-known finite nature of oil reservoirs [15] has changed the world's perspective and led several research groups to work towards sustainable solutions to yield a less oil dependent energy grid. This change in global paradigm has also raised concerns regarding global warming, sustainability, and several other environmental problems [16] in which, in a way or another, microalgae cultivation has room as a promising alternative for replacing existing processes [17].

In fact, microalgae cultivation not only fulfils the requirements for an alternative energy source to cover future demand of energy, but also overcomes land based renewable energy crops due to its high productivity (per area-time) and use of non-arable lands [18]. These features of microalgae have been cited as the reasons to invest significant amounts of capital required to turn algae technology mature and economically feasible and able to offset oil-based processes on renewable fuel production [19]. 
On the other hand, the steep rise of the world's population in the coming decades is predicted to make achieving adequate nutrition a growing global concern, which puts microalgae cultivation as potential alternative food crop for both human and animals [18].

Microalgae cultivation can provide a diverse number of essential nutrients [20]. Combined with the ability of microalgae to grow rapidly and produce more biomass per hectare than vascular plants, this process can soon cost-effectively satisfy the need for products of high nutritional value at large scale. Besides, an extensive large-scale cultivation would not put a stress on land availability, since it uses both land and water sources that are unsuitable for agriculture.

This review will present comprehensively the main aspects of microalgae technology from their cultivation to the production of high value molecules. Therefore, this manuscript aims to establish some basic knowledge for any non-specialist reader who wants an introduction to microalgal technology. This is accomplished by addressing the generalist selection and isolation methods, as well as cultivation modes and their role on the modern drug discovery and subsequently provides a solid foundation for future researchers.

\section{SELECTION AND ISOLATION}

The wide range of applications in which microalgae may play a key role in the future, e.g. phytoremediation or carbon capture [21], requires their full characterisation in order to select the most promising species for each use, thus contributing to the understanding and success of microalgal processes [22].

Microalgae selection and characterisation consist of: identifying species with higher growth rate and high conversion yield; defining the best cultivation mode to maximise production of the target molecule (or biomass); using low-cost growth medium; selecting a harvest method that maximises nutrient recovery and reuse as well as product recovery and global yield [23]. Table 1 presents a set of desirable features of microalgae and their main advantages.

Table 1: Desirable features of microalgae for mass production. Adapted from Griffiths et al. [24]; Klein et al. [25].

Feature

High growth rate

High product content

Growth in extreme

environments

Large cell size, colonial, or filamentous morphology

Wide tolerance to environmental conditions

High $\mathrm{CO}_{2}$ tolerance and absorption

Shear force tolerance

Tolerance to contaminants

Absence of production of self-inhibitors

\section{Advantages}

- Competitive advantage over competing species

- Smaller area of crop required

- Higher biomass value

- Lower contamination rates and degradation rates

- Lower costs for harvesting and processing

- Lower control of required culture conditions. Growth over the range of seasons and ambient climatic conditions

- Increased potential for $\mathrm{CO}_{2}$ sequestration and use of $\mathrm{CO}_{2}$ residues

- Cheaper pumping methods and medium

- Potential growth in polluted water and flue gases containing high $\mathrm{CO}_{2}, \mathrm{NO}_{x}$, and $\mathrm{SO}_{x}$

- Smaller self-inhibition of growth (at high biomass densities) 
Their short life cycle (hours to days), high nutrient absorption rate [26], and capability to grow in both fresh and marine waters [1] allow researchers to process the screening of several species in miniaturised systems, reducing development costs and intensifying process design. These features, associated with their high photosynthetic efficiency and possibility of cultivation in either mixotrophic or heterotrophic modes are their main advantages compared to other photosynthetic organisms [27].

While the synergetic effect of bacteria-algae consortium has been previously reported [28], algal species are often isolated and identified prior to their use following mostly traditional microbiology techniques. Isolation promotes separation from mixed cultures or environmental samples and must be chosen according to sample conditions and microalgae type.

Their selection and isolation follow established and well-known microbiological methods. Isolation by serial dilution consists in diluting successively a non-pure algae sample to decrease cellular density per volume to such level that a simple seeding from this diluted solution will likely originate a single-type colony, as described by Thomas et al. [29]. Isolation using agar plates follows the same procedure for bacteria and other microorganisms: a solid agar-nutrient medium is prepared using a suitable composition based on the natural environment of microalgae or desirable features [30]. The medium will not only provide the conditions for organisms to grow but will also prevent contamination from external sources by manipulating its $\mathrm{pH}$, temperature, and composition. The technique per se consists in spreading evenly a small fraction of the inoculum, usually using platinum-rhodium loops, throughout the surface of the agar plate. Stanbury et al. [31] described these methods in detail. In some cases, it is necessary to combine isolation techniques with the use of antimicrobials or use of filtration or even greater dilutions in the isolation of the microalga. Beware that particular species, such as Arthrospira platensis, will require specially designed methods, as well as a suitable nutrient medium and photoperiod.

\section{CULTIVATION MODES}

As microalgae cultivation technology is one of the factors considered to be restricting an economically feasible industrial-scale production [32], it is necessary to develop lower-cost operation modes which can increase biomass (or a chosen target molecule) production and thereby reduce the cultivation costs.

Though most research is realized through photoautotrophic and heterotrophic cultivation modes, there are algae that can grow under mixotrophic [33] and photoheterotrophic modes [34]. On autotrophic cultivation, microalgae generate organic compounds by using sunlight to process an inorganic carbon source, mainly $\mathrm{CO}_{2}$ [35]. Carbon dioxide requirements are usually met by dispersing atmospheric air using a submerged liquid/gas equipment [36]. The open pond system, which has been used since the late 1950s due to its simplicity, is the most primitive system for their cultivation [34]. However, its susceptibility to contamination by other microalgae and microorganisms [37], and temperature variations throughout day/light periods [38] makes the open pond system not suitable for large scale culture [34].

Closed photobioreactors were developed to overcome the abovementioned weaknesses (among others) of open pond systems, resulting in a series of reactor designs [39] which increased surface to volume ratio and system reliability [40]. An aseptic, low-cost and weather independent process is still a challenge, since closed systems costs are substantially higher than open pond systems [41] and thereby prohibitive depending on the target product.

Microalgae growing under heterotrophic cultivation depend upon metabolism of organic compounds available that will provide carbon source and energy [42] and have a much smaller surface to volume ratio requirement than autotrophic cultivations [43] due to their ability to grow under dark conditions [42].

Heterotrophic microalgae culture has proven to be able to accelerate both cell growth rate [34] and cell density [44], decreasing costs for their cultivation and harvesting. Also, 
glucose used as main source for heterotrophic cultivation has been gradually replaced by low-cost alternatives, such as the hydrolysed product obtained from cellulosic materials [45], glycerol [42], or wastewater from several sources [46].

Despite an increase of contamination susceptibility [47], usage of an organic carbon source offers the opportunity to dramatically reduce microalgae cultivation by reusing surplus nutrient found in several factory effluents [48-50] or domestic wastewater [34]. Such potential led researchers to combine microalgae cultivation with wastewater treatment, yielding reports which describe the outstanding production of lipids [51] and biomass [52] as well as nitrogen and phosphorus assimilation [53], when growing under heterotrophic mode.

Mixotrophic cultivations have been summarized as a two-stage mode in which the microalgae will experience a high initial organic carbon content but will be induced to assimilate $\mathrm{CO}_{2}$ autotrophically due to organic matter depletion [34] and produce oxygen through photosynthesis [54]. By integrating a dark-light cycle to a mixotrophic cultivation, the microalgae will grow under autotrophic and heterotrophic optimum conditions, combining the advantages of both cultivation modes, and thus increase biomass and lipids [55].

The existence of multiple cultivation modes, as described above, implies that such organisms assimilate carbon through various metabolic pathways, both in presence or absence of light [56]. Venkata Mohan et al. [57] thoroughly presented metabolism schematics for each cultivation mode. In summary, carbon conversion to glucose requires, under photosynthetic light conditions, three ATP and two NADPH, which were generated during the light absorption process [57]. During the dark-cycle, however, carbon dioxide fixation occurs in a three-step reaction which yields glucose. Figure 1 presents a simplified version of the mixotrophic carbon fixation under nutrient limiting conditions that lead to lipid biosynthesis.



Figure 1. Schematic diagram for mixotrophic carbon fixation and lipid synthesis. Adapted from Venkata Mohan et al. [57].

Mixotrophism makes use of the most advantages of heterotrophic and autotrophic modes by using either light or carbon as the energy source on its nutrition pathways and therefore having no light dependency [21]. In such conditions, acetyl-CoA will be produced 
and maintained from both the $\mathrm{CO}_{2}$ fixation and extra cellular organic carbon (see Figure 1), showing reduced photo inhibition. Mixotrophic cultures are often observed in ecological water bodies where they are supported by both chemical, physical, and organic activity of the biota [57].

Zhan et al. [34] assessed some of the main advantages and disadvantages of mixotrophic cultivation, highlighting differences regarding its energy conversion efficiency, photosystem activity, and ability to preserve valuable pigments in illuminated conditions, such as carotenoids and chlorophylls, and concluded those depend mostly on microalgae species and the source of organic matter.

\section{GREEN PRODUCTS POTENTIAL}

Despite our civilisation thriving throughout the surface of the $70 \%$ water-covered planet, it was not before the 1960s that research regarding Marine Natural Products (MNP) was engaged, focusing on drug discovery only during the 1980s [58]. During the following decades, over 28,000 novel compounds were being discovered every year [59], which still leaves an estimated number of $91 \%$ of marine species (vegetal and animal) awaiting description [60].

The microalgae biomass market has a size of about 5,000 t/year of dry matter and generates a turnover of capital of US $\$ 1.25 \times 10^{9}$ per year [61]. While profitability of microalgae-based processes is still questionable [62], energy-efficient and sustainable production will not only balance environmental and business interests but it will also be very good for publicity. Seemingly, the feasibility and sustainability of an industrial scale microalgae industry seems to depend upon the successful development of a microalgae biorefinery.

The concept of biorefinery derives directly from the petroleum counterpart, where a raw product is converted into several other value-added products. While essentially similar to the traditional refinery, this biorefinery would process microalgae biomass and convert it to a wide range of product, such as biofuels, pharmaceuticals, food, and other products [22] (see Figure 2). Besides, it represents a promising pathway to investigate the integration of carbon mitigation processes and the use of alternative growth mediums.

An alternative growth medium often can use wastewater in its composition in virtue of the presence of several required components. The cost of biomass production will vary according to the amount of nutrients used to supplement those already in the wastewater. Consequently, the cost will be smaller than for a cultivation which uses a synthetic medium.

The wastewater treatment by microalgae was studied on effluents from paper industry, fish farming [49], petroleum industries, pharmaceutical industry [63], textile industry [64], sugarcane [65], and many others [66]. Such are usually combined with anaerobic pre-treatment to avoid algal growth inhibition caused by the high COD concentration [67]. Wang et al. [67] accessed the potential of algae-bacteria association as a major strategy for cost reduction. It is believed that the associated bacteria reduce photosynthetic oxygen tension by consuming the $\mathrm{O}_{2}$ produced by the algae as their electron acceptor, and supply essential nutrients like vitamins and other compounds [68], and even allow microalgae growth under iron deficient conditions [69].



Figure 2. Process Flowchart for a Multiple Products Conceptual Biorefinery 
Among the many bioactive compounds known to be produced by microalgae are vitamins, lipids, pigments, lipids, and polysaccharides [8]. The very similar nature of all compounds produced during microalgae cultivation, the downstream of these molecules in a cost-effective manner are the main challenges in establishing a microalgae-based bioprocess. Some of those chemicals have demonstrated anticancer [70], anti-infective [71], antioxidant [72], immunostimulatory [73], anti-inflammatory [74] activities, and hypocholesterolaemia effect [75]. The following topics describe briefly three of the most researched biological activities observed in microalgae-derived bioproducts, while details regarding their mechanism and purification procedures are left intentionally out of this review.

\section{Antioxidant Activity}

Antioxidant is a biological macromolecule which protects organisms or their vital compounds against oxidative radicals [76]. Many natural antioxidants are often components of cosmetics as an active ingredient or for maintaining stability, protecting, and preserving properties of the product. While antioxidant compounds are essential for cosmetics production, their application in functional food and nutraceuticals is still growing $[77,78]$. The antioxidant capacity of microalgae-derived products is especially desired in pharmaceutical applications, mostly for oxidation-associated diseases [79].

Microalgae, as photosynthetic organisms, are subjected to elevated concentrations of reactive oxygen species (ROS) and have developed a mechanism to protect themselves from the free radicals. The produced antioxidants are the mechanism's foundation, preventing cell damage by preventing ROS accumulation in the microalgae [80]. Given biodiversity of microalgae, easy cultivation, and growth modulation, they can be considered among the top natural resources with outstanding antioxidant potential [81].

Ita et al. [82] tested methanolic extracts from three different microalgae: I. galbana clone Tahiti, T. chuii, and D. salina. All three showed high antioxidant activity, Dunalliela sp. and Tetraselmis chuii having the highest ones, $D$. salina produced the best inhibition result of $62.19 \%$ at $500 \mathrm{ppm}$. Meanwhile T. chuii showed the best result with $71.36 \%$ of inhibition at 1000 ppm. There are many other reports of antioxidant activity found in microalgae species, Synechocystis [83], Chlorella [72], and Scenedesmus subspicatus [84].

\section{Anticancer Activity}

World Cancer Report of 2014 by the International Agency for Research on Cancer (IRAC), from World Health Organization (WHO), states that cancer is a public health issue, manly among developing countries where 20 million new cases are expected within the next decades [85]. Cancer is a leading cause of death worldwide, accounting for 8.8 million deaths in 2015 , according to WHO.

Natural products and their derivatives represent more than $50 \%$ of all drugs in clinical use in the world and almost $60 \%$ of approved drugs for cancer treatment [86]. Bioactive extracts from marine cyanobacteria are effective in destroying cancer cells by inducing apoptotic death or affecting cell signalling by activation of protein kinase $\mathrm{C}$ family signalling enzymes [86].

The number of studies on finding new compounds with anticancer properties has grown in the past years. Lauritano et al. [74] evaluated the anticancer properties of 32 microalgal species by testing the antiproliferative activity against human melanoma cells (A2058). Somasekharan et al. [87] observed from a marine Canadian microalgae extract the inhibition of colony forming ability of cancer cells and suspended cancer cells were the preferential killed.

Stevenson et al. [88] identified scytonemin, an isolate from Stigonema sp., as a protein serine/threonine kinase inhibitor. Scytonemin regulates mitotic spindle formation as well as enzyme kinases involved in cell cycle control and the compound also inhibits proliferation of human fibroblasts and endothelial cells [88]. 
Thus scytonemin may provide an excellent drug, as protein kinase inhibitors have antiproliferative and anti-inflammatory activities [89]. Chen et al. [73] extracted sulfated polysaccharides from Tribonema sp. (TSP) a filamentous microalgae and tested in liver cancer cells, HepG2. Using MTT test indicated that the TSP has anticancer activity and is result of induced cell apoptosis.

\section{Anti-inflammatory Activity}

The inflammatory response to an injury stimulus can come from an infection or from cells stimulated by physical damage, neuropeptides, or radiation [90]. Independently from which was the first stimulus, the classic inflammatory response includes pain, heat, blush, and tumour. Temporary vasodilatation starts increasing the permeability of blood borne defences to the affected area [91].

Guzmán et al. [92] found that aqueous extracts of $C$. stigmatophora and $P$. tricornutum could reduce carrageenan-induced paw oedema in rats. With a dose of $250 \mathrm{mg} / \mathrm{kg}$, the highest, the inflammation was reduced by $90 \%$ and $87 \%$, respectively. The algal extracts showed an anti-inflammatory activity that is about $25 \%-30 \%$ that of the reference anti-inflammatory used (indomethacin). This is a reasonable result considering that a pure synthetic product was compared with a crude extract which might contain other elements that could interfere with its activity.

Spirulina is a filamentous microalgae with a high nutritional value and it is widely used as nutraceutical food supplement worldwide [93, 94]. Apart from its nutritional importance, it also shows medical properties, including anti-inflammatory activity. A component present in Spirulina called phycocyanin inhibits pro-inflammatory cytokine formation, as TNF $\alpha$, decreases prostaglandin $\mathrm{E}(2)$ production, and suppresses cyclooxygeanase-2 (COX-2) expression, as Khanra et al. [94] reported.

$\beta$-carotene, another compound present in Spirulina, when accumulated suppresses the transcription of $\mathrm{IL}-1 \beta, \mathrm{IL}-6$, and $\mathrm{IL}-12$, inflammatory cytokines, in macrophage cell line stimulated by lipopolysaccharide (LPS) or IFNy [93].

\section{FINAL CONSIDERATIONS}

In this review, we have presented a set of core aspects regarding microalgae cultivation and some of the high value bioactive molecules produced. A variety of modes in which these organisms can be cultivated were also introduced, allowing to explore their biotechnological potential and to favour bio-based processes. While a full extent discussion of the microalgae subject would yield a prohibitively lengthy manuscript, this review provides a comprehensive list of scientific articles to enrich the reader's knowledge and lays the foundation for more complex concepts such as integrated biorefineries. The very same principles that were introduced in this article form the basis of the wide range of applications derived from microalgae technology and its impact on the worldwide implementation, e.g. carbon mitigation strategies.

\section{ACKNOWLEDGEMENT}

Authors would like to acknowledge the financial support of CAPES (Coordenação de Aperfeiçoamento de Pessoal de Nível Superior), and CNPq (Conselho Nacional de Desenvolvimento Científico e Tecnológico - Process 152962/2018-2) for the financial support.

\section{REFERENCES}

1. Daneshvar E., Zarrinmehr M.J., Hashtjin A.M., Farhadian O., Bhatnagar A. Versatile applications of freshwater and marine water microalgae in dairy wastewater treatment, lipid extraction and tetracycline biosorption. Bioresour. Technol. 2018;268:523-30. 
2. Shuba Eyasu S., Kifle D. Microalgae to biofuels: 'Promising' alternative and renewable energy, review. Renewable Sustainable Energy Rev. 2018;81:743-55.

3. Vu C.H.T., Lee H.-G., Chang Y.K., Oh H.-M. Axenic cultures for microalgal biotechnology: establishment, assessment, maintenance, and applications. Biotechnol. Adv. 2018;36(2):380-96.

4. Hakobyan L., Gabrielyan L., Trchounian A. Biohydrogen by Rhodobacter sphaeroides during photo-fermentation: Mixed vs. sole carbon sources enhance bacterial growth and $\mathrm{H} 2$ production. Int. J. Hydrogen Energy. 2019;44(2):674-9.

5. Postma P.R., 't Lam G.P., Barbosa M.J., Wijffels R.H., Eppink M.H.M., Olivieri G. Microalgal Biorefinery for Bulk and High-Value Products: Product Extraction Within Cell Disintegration. In: Miklavcic D, editor. Handbook of Electroporation. Cham: Springer International Publishing; 2016. p. 1-20.

6. Malcata F.X., Pinto I.S., Guedes A.C. Marine Macro-and Microalgae: An Overview: CRC Press; 2018.

7. Bassham J.A., Egeter H., Edmonston F., Kirk M. The effects of 8-metyyl lipoic acid on the evolution of oxygen and reduction of carbon dioxide during photosynthesis. Biochem. Biophys. Res. Commun. 1963;13(2):144-9.

8. Perin G., Bellan A., Bernardi A., Bezzo F., Morosinotto T. The potential of quantitative models to improve microalgae photosynthetic efficiency. Physiol. Plant. 2019;0(0).

9. Clark R.L., McGinley L.L., Purdy H.M., Korosh T.C., Reed J.L., Root T.W., et al. Light-optimized growth of cyanobacterial cultures: Growth phases and productivity of biomass and secreted molecules in light-limited batch growth. Metab. Eng. 2018;47:230-42.

10. Neumann U., Derwenskus F., Gille A., Louis S., Schmid-Staiger U., Briviba K., et al. Bioavailability and Safety of Nutrients from the Microalgae Chlorella vulgaris, Nannochloropsis oceanica and Phaeodactylum tricornutum in C57BL/6 Mice. Nutrients. 2018;10(8):965.

11. Guiry M.D. How Many Species of Algae are there? J. Phycol. 2012;48(5):1057-63.

12. t Lam G.P., Vermuë M.H., Eppink M.H.M., Wijffels R.H., van den Berg C. Multi-Product Microalgae Biorefineries: From Concept Towards Reality. Trends Biotechnol. 2018;36(2):216-27.

13. Norton T.A., Melkonian M., Andersen R.A. Algal biodiversity. Phycologia. 1996;35(4):308-26.

14. Demirbas A. Biodiesel from oilgae, biofixation of carbon dioxide by microalgae: A solution to pollution problems. ApEn. 2011;88(10):3541-7.

15. Owen N.A., Inderwildi O.R., King D.A. The status of conventional world oil reserves-Hype or cause for concern? Energy Policy. 2010;38(8):4743-9.

16. Brandt M.J., Johnson K.M., Elphinston A.J., Ratnayaka D.D. Chapter 13 - Energy Use, Sustainability and Waste Treatment. Twort's Water Supply (Seventh Edition). Boston: Butterworth-Heinemann; 2017. p. 553-80.

17. Baicha Z., Salar-García M.J., Ortiz-Martínez V.M., Hernández-Fernández F.J., de los Ríos A.P., Labjar N., et al. A critical review on microalgae as an alternative source for bioenergy production: A promising low cost substrate for microbial fuel cells. Fuel Process. Technol. 2016;154:104-16.

18. Sun J., Xiong X., Wang M., Du H., Li J., Zhou D., et al. Microalgae biodiesel production in China: A preliminary economic analysis. Renewable Sustainable Energy Rev. 2019;104:296-306.

19. Shuba E.S., Kifle D. Microalgae to biofuels:'Promising'alternative and renewable energy, review. Renewable and Sustainable Energy Reviews. 2018;81:743-55.

20. de Carvalho J.C., Sydney E.B., Tessari L.F.A., Soccol C.R. Culture media for mass production of microalgae. Biofuels from Algae: Elsevier; 2019. p. 33-50.

21. Sydney E.B., Sydney A.C.N., de Carvalho J.C., Soccol C.R. Potential carbon fixation of industrially important microalgae. Biofuels from Algae: Elsevier; 2019. p. 67-88.

22. Yadav G., Sen R. Sustainability of Microalgal Biorefinery: Scope, Challenges, and Opportunities. Sustainable Energy Technology and Policies: Springer; 2018. p. 335-51.

23. Savage P.E., Hestekin J.A. A perspective on algae, the environment, and energy. Environmental Progress \& Sustainable Energy. 2013;32(4):877-83.

24. Griffiths M.J., Harrison S.T. Lipid productivity as a key characteristic for choosing algal species for biodiesel production. J. Appl. Phycol. 2009;21(5):493-507. 
25. Klein B.C., Bonomi A., Maciel Filho R. Integration of microalgae production with industrial biofuel facilities: A critical review. Renewable Sustainable Energy Rev. 2018;82:1376-92.

26. Lehmuskero A., Chauton M.S., Boström T. Light and photosynthetic microalgae: A review of cellular-and molecular-scale optical processes. PrOce. 2018.

27. Morales-Sánchez D., Martinez-Rodriguez O.A., Martinez A. Heterotrophic cultivation of microalgae: production of metabolites of commercial interest. J. Chem. Technol. Biotechnol. 2017;92(5):925-36.

28. Xu Y., Wang Y., Yang Y., Zhou D. The role of starvation in biomass harvesting and lipid accumulation: Co-culture of microalgae-bacteria in synthetic wastewater. Environmental Progress \& Sustainable Energy. 2016;35(1):103-9.

29. Thomas P., Sekhar A.C., Upreti R., Mujawar M.M., Pasha S.S. Optimization of single plate-serial dilution spotting (SP-SDS) with sample anchoring as an assured method for bacterial and yeast cfu enumeration and single colony isolation from diverse samples. Biotechnology Reports. 2015;8:45-55.

30. Pereira H., Páramo J., Silva J., Marques A., Barros A., Maurício D., et al. Scale-up and large-scale production of Tetraselmis sp. CTP4 (Chlorophyta) for $\mathrm{CO} 2$ mitigation: from an agar plate to $100 \mathrm{~m} 3$ industrial photobioreactors. Scientific reports. 2018;8(1):5112.

31. Stanbury P.F., Whitaker A., Hall S.J. Chapter 3 - The isolation and improvement of industrially important microorganisms. Principles of Fermentation Technology (Third Edition). Oxford: Butterworth-Heinemann; 2017. p. 75-211.

32. Chen H., Qiu T., Rong J., He C., Wang Q. Microalgal biofuel revisited: An informatics-based analysis of developments to date and future prospects. ApEn. 2015;155:585-98.

33. Kharati-Koupaei M., Moradshahi A. Effects of Sodium Nitrate and Mixotrophic Culture on Biomass and Lipid Production in Hypersaline Microalgae Dunaliella Viridis Teod. Braz. Arch. Biol. Technol. 2016;59.

34. Zhan J., Rong J., Wang Q. Mixotrophic cultivation, a preferable microalgae cultivation mode for biomass/bioenergy production, and bioremediation, advances and prospect. Int. J. Hydrogen Energy. 2017;42(12):8505-17.

35. Uggetti E., Sialve B., Hamelin J., Bonnafous A., Steyer J.-P. CO2 addition to increase biomass production and control microalgae species in high rate algal ponds treating wastewater. Journal of CO2 Utilization. 2018;28:292-8.

36. López-Rosales L., Sánchez-Mirón A., Contreras-Gómez A., García-Camacho F., Battaglia F., Zhao L., et al. Characterization of bubble column photobioreactors for shear-sensitive microalgae culture. Bioresour. Technol. 2019;275:1-9.

37. Deruyck B., Thi Nguyen K.H., Decaestecker E., Muylaert K. Modeling the impact of rotifer contamination on microalgal production in open pond, photobioreactor and thin layer cultivation systems. Algal Research. 2019;38:101398.

38. Kannan D.C., Venkat D. An open outdoor algal growth system of improved productivity for biofuel production. J. Chem. Technol. Biotechnol. 2019;94(1):222-35.

39. Acién F.G., Molina E., Reis A., Torzillo G., Zittelli G.C., Sepúlveda C., et al. Photobioreactors for the production of microalgae A2 - Gonzalez-Fernandez, Cristina. In: Muñoz R, editor. Microalgae-Based Biofuels and Bioproducts: Woodhead Publishing; 2017. p. 1-44.

40. Anyanwu R.C., Rodriguez C., Durrant A., Olabi A.G. Microalgae Cultivation Technologies. Reference Module in Materials Science and Materials Engineering: Elsevier; 2018.

41. Costa J.A.V., Freitas B.C.B., Santos T.D., Mitchell B.G., Morais M.G. Open pond systems for microalgal culture. Biofuels from Algae: Elsevier; 2019. p. 199-223.

42. Hu J., Nagarajan D., Zhang Q., Chang J.-S., Lee D.-J. Heterotrophic cultivation of microalgae for pigment production: A review. Biotechnol. Adv. 2018;36(1):54-67.

43. Mazumdar N., Novis P.M., Visnovsky G., Gostomski P.A. Effect of nutrients on the growth of a new alpine strain of Haematococcus (Chlorophyceae) from New Zealand. Phycol. Res. 2019;67(1):21-7.

44. Mantzorou A., Ververidis F. Microalgal biofilms: A further step over current microalgal cultivation techniques. Sci. Total Environ. 2018. 
45. Nguyen H.C., Su C.-H., Yu Y.-K., Huong D.T.M. Sugarcane bagasse as a novel carbon source for heterotrophic cultivation of oleaginous microalga Schizochytrium sp. Ind Crops Prod. 2018;121:99-105.

46. Cassini S.T., Francisco S.A., Antunes P.W.P., Oss R.N., Keller R. Harvesting Microalgal Biomass grown in Anaerobic Sewage Treatment Effluent by the Coagulation-Flocculation Method: Effect of pH. Braz. Arch. Biol. Technol. 2017;60.

47. Abinandan S., Subashchandrabose S.R., Venkateswarlu K., Megharaj M. Nutrient removal and biomass production: advances in microalgal biotechnology for wastewater treatment. Crit. Rev. Biotechnol. 2018;38(8):1244-60.

48. Ray M., Kumar N., Kumar V., Negi S., Banerjee C. Microalgae: A Way Forward Approach Towards Wastewater Treatment and Bio-Fuel Production. Applied Microbiology and Bioengineering: Elsevier; 2019. p. 229-43.

49. Osundeko O., Ansolia P., Gupta S.K., Bag P., Bajhaiya A.K. Promises and Challenges of Growing Microalgae in Wastewater. Water Conservation, Recycling and Reuse: Issues and Challenges: Springer; 2019. p. 29-53.

50. Vaz B.d.S., Costa J.A.V., Morais M.G. Use of Solid Waste from Thermoelectric Plants for the Cultivation of Microalgae. Braz. Arch. Biol. Technol. 2016;59.

51. Rismani S., Shariati M. Changes of the Total Lipid and Omega-3 Fatty Acid Contents in two Microalgae Dunaliella Salina and Chlorella Vulgaris Under Salt Stress. Braz. Arch. Biol. Technol. 2017;60.

52. Ghidossi T., Marison I., Devery R., Gaffney D., Forde C. Characterization and optimization of a fermentation process for the production of high cell densities and lipids using heterotrophic cultivation of chlorella protothecoides. Industrial Biotechnology. 2017;13(5):253-9.

53. Chen X., Li Z., He N., Zheng Y., Li H., Wang H., et al. Nitrogen and phosphorus removal from anaerobically digested wastewater by microalgae cultured in a novel membrane photobioreactor. Biotechnology for biofuels. 2018;11(1):190.

54. Rincon S.M., Urrego N.F., Avila K.J., Romero H.M., Beyenal H. Photosynthetic activity assessment in mixotrophically cultured Chlorella vulgaris biofilms at various developmental stages. Algal Research. 2019;38:101408.

55. Ren H.-Y., Xiao R.-N., Kong F., Zhao L., Xing D., Ma J., et al. Enhanced biomass and lipid accumulation of mixotrophic microalgae by using low-strength ultrasonic stimulation. Bioresour. Technol. 2019;272:606-10.

56. Baldisserotto C., Sabia A., Ferroni L., Pancaldi S. Biological aspects and biotechnological potential of marine diatoms in relation to different light regimens. World J. Microbiol. Biotechnol. 2019;35(2):35.

57. Venkata Mohan S., Rohit M.V., Chiranjeevi P., Chandra R., Navaneeth B. Heterotrophic microalgae cultivation to synergize biodiesel production with waste remediation: Progress and perspectives. Bioresour. Technol. 2015;184:169-78.

58. Barbosa M., Lopes G., Andrade P.B., Valentão P. Bioprospecting of Brown Seaweeds for Biotechnological Applications: Phlorotannin Actions in Inflammation and Allergy Network. Trends Food Sci. Technol. 2019.

59. Blunt J.W., Copp B.R., Keyzers R.A., Munro M.H.G., Prinsep M.R. Marine natural products. Nat. Prod. Rep. 2015;32(2):116-211.

60. Romano G., Costantini M., Sansone C., Lauritano C., Ruocco N., lanora A. Marine microorganisms as a promising and sustainable source of bioactive molecules. Mar Environ Res. 2016.

61. Rajendran K., Browne J.D., Murphy J.D. What is the level of incentivisation required for biomethane upgrading technologies with carbon capture and reuse? Renewable energy. 2019;133:951-63.

62. Raslavičius L., Striūgas N., Felneris M. New insights into algae factories of the future. Renewable Sustainable Energy Rev. 2018;81:643-54.

63. Polishchuk A., Valev D., Tarvainen M., Mishra S., Kinnunen V., Antal T., et al. Cultivation of Nannochloropsis for eicosapentaenoic acid production in wastewaters of pulp and paper industry. Bioresour. Technol. 2015;193:469-76. 
64. Wu J.-Y., Lay C.-H., Chen C.-C., Wu S.-Y. Lipid accumulating microalgae cultivation in textile wastewater: Environmental parameters optimization. J Taiwan Inst Chem E. 2017.

65. Ramirez N.N.V., Farenzena M., Trierweiler J.O. Growth of microalgae Scenedesmus sp in ethanol vinasse. Braz. Arch. Biol. Technol. 2014;57:630-5.

66. Mark lbekwe A., Murinda S.E., Murry M.A., Schwartz G., Lundquist T. Microbial community structures in high rate algae ponds for bioconversion of agricultural wastes from livestock industry for feed production. Sci. Total Environ. 2017;580:1185-96.

67. Wang Y., Ho S.-H., Cheng C.-L., Guo W.-Q., Nagarajan D., Ren N.-Q., et al. Perspectives on the feasibility of using microalgae for industrial wastewater treatment. Bioresour. Technol. 2016;222:485-97.

68. Hu X., Meneses Y.E., Stratton J., Wang B. Acclimation of consortium of micro-algae help removal of organic pollutants from meat processing wastewater. Journal of Cleaner Production. 2019;214:95-102.

69. Devadasu E., Chinthapalli D.K., Chouhan N., Madireddi S.K., Rasineni G.K., Sripadi P., et al. Changes in the photosynthetic apparatus and lipid droplet formation in Chlamydomonas reinhardtii under iron deficiency. Photosynth. Res. 2019;139(1-3):253-66.

70. Dewi I.C., Falaise C., Hellio C., Bourgougnon N., Mouget J.-L. Anticancer, Antiviral, Antibacterial, and Antifungal Properties in Microalgae. Microalgae in Health and Disease Prevention: Elsevier; 2018. p. 235-61.

71. Lauritano C., Martín J., de la Cruz M., Reyes F., Romano G., lanora A. First identification of marine diatoms with anti-tuberculosis activity. Scientific reports. 2018;8(1):2284.

72. Agregán R., Munekata P., Franco D., Carballo J., Barba F., Lorenzo J. Antioxidant potential of extracts obtained from macro-(Ascophyllum nodosum, Fucus vesiculosus and Bifurcaria bifurcata) and micro-algae (Chlorella vulgaris and Spirulina platensis) assisted by ultrasound. Medicines. 2018;5(2):33.

73. Chen X., Song L., Wang H., Liu S., Yu H., Wang X., et al. Partial Characterization, the Immune Modulation and Anticancer Activities of Sulfated Polysaccharides from Filamentous Microalgae Tribonema sp. Molecules. 2019;24(2):322.

74. Lauritano C., Andersen J.H., Hansen E., Albrigtsen M., Escalera L., Esposito F., et al. Bioactivity Screening of Microalgae for Antioxidant, Anti-Inflammatory, Anticancer, Anti-Diabetes, and Antibacterial Activities. Frontiers in Marine Science. 2016;3(68).

75. Martínez-Bisbal M.C., Carbó Mestre N., Martínez-Máñez R., Bauzá J., Alcañiz Fillol M. Microalgae degradation follow up by voltammetric electronic tongue, impedance spectroscopy and NMR spectroscopy. Sensors Actuators B: Chem. 2019;281:44-52.

76. Tessmer Scaglioni P., Quadros L., de Paula M., Badiale Furlong V., Abreu P.C., Badiale-Furlong E. Inhibition of Enzymatic and Oxidative Processes by Phenolic Extracts from Spirulina sp. and Nannochloropsis sp. Food Technol. Biotechnol. 2018;56(3):344-53.

77. Patel A., Matsakas L., Hrůzová K., Rova U., Christakopoulos P. Biosynthesis of Nutraceutical Fatty Acids by the Oleaginous Marine Microalgae Phaeodactylum tricornutum Utilizing Hydrolysates from Organosolv-Pretreated Birch and Spruce Biomass. Mar. Drugs. 2019;17(2):119.

78. Joshi S., Kumari R., Upasani V.N. Applications of algae in cosmetics: An overview. Int. J. Innov. Res. Sci. Eng. Technol. 2018;7:1269-78.

79. Taleb A., Ahmad K.A., Ihsan A.U., Qu J., Lin N., Hezam K., et al. Antioxidant effects and mechanism of silymarin in oxidative stress induced cardiovascular diseases. Biomed. Pharmacother. 2018;102:689-98.

80. Sun X.-M., Geng L.-J., Ren L.-J., Ji X.-J., Hao N., Chen K.-Q., et al. Influence of oxygen on the biosynthesis of polyunsaturated fatty acids in microalgae. Bioresour. Technol. 2018;250:868-76.

81. Sathasivam R., Ki J.-S. A review of the biological activities of microalgal carotenoids and their potential use in healthcare and cosmetic industries. Mar. Drugs. 2018;16(1):26.

82. Ita W., Muhammad Z., Hermien Pancasakti K., Ragil S., Yann H., Vincent L., et al. Antioxidant activity of three microalgae Dunaliella salina, Tetraselmis chuii and Isochrysis galbana clone Tahiti. IOP Conference Series: Earth and Environmental Science. 2017;55(1):012067. 
83. Blagojević D., Babić O., Rašeta M., Šibul F., Janjušević L., Simeunović J. Antioxidant activity and phenolic profile in filamentous cyanobacteria: The impact of nitrogen. J. Appl. Phycol. 2018;30:2337-46.

84. Dantas D.M.d.M., Oliveira Y.B.d.C., Costa R.M.P.B., das Graças Carneiro-da-Cunha M., Gálvez A.O., de Souza Bezerra R. Evaluation of antioxidant and antibacterial capacity of green microalgae Scenedesmus subspicatus. Food Sci. Technol. Int. 2019:1082013218825024.

85. INCA N.C.I. Cancer Incidence in Brazil. 2018.

86. Sithranga Boopathy N., Kathiresan K. Anticancer Drugs from Marine Flora: An Overview. Journal of Oncology. 2010;2010.

87. Somasekharan S.P., El-Naggar A., Sorensen P.H., Wang Y., Cheng H. An Aqueous Extract of Marine Microalgae Exhibits Antimetastatic Activity through Preferential Killing of Suspended Cancer Cells and Anticolony Forming Activity. Evidence-Based Complementary and Alternative Medicine. 2016;2016:8.

88. Stevenson C.S., Capper E.A., Roshak A.K., Marquez B., Eichman C., Jackson J.R., et al. The Identification and Characterization of the Marine Natural Product Scytonemin as a Novel Antiproliferative Pharmacophore. J. Pharmacol. Exp. Ther. 2002;303(2):858.

89. Rastogi R.P., Sinha R.P. Biotechnological and industrial significance of cyanobacterial secondary metabolites. Biotechnol. Adv. 2009;27(4):521-39.

90. Chen L., Deng H., Cui H., Fang J., Zuo Z., Deng J., et al. Inflammatory responses and inflammation-associated diseases in organs. Oncotarget. 2017;9(6):7204-18.

91. Greene C. The Blood-brain Barrier in Neuropsychiatric Disorders: Trinity College Dublin; 2018.

92. Guzmán S., Gato A., Calleja J.M. Antiinflammatory, analgesic and free radical scavenging activities of the marine microalgae Chlorella stigmatophora and Phaeodactylum tricornutum. Phytother. Res. 2001;15(3):224-30.

93. Andrade L., Andrade C., Dias M., Nascimento C., Mendes M. Chlorella and Spirulina Microalgae as Sources of Functional Foods. Nutraceuticals, and Food Supplements. 2018:45-58.

94. Khanra S., Mondal M., Halder G., Tiwari O., Gayen K., Bhowmick T.K. Downstream processing of microalgae for pigments, protein and carbohydrate in industrial application: A review. Food Bioprod. Process. 2018.

2018 by the authors. Submitted for possible open access publication under the terms and conditions of the Creative Commons Attribution (CC BY NC) license (http://creativecommons.org/licenses/by-nc/4.0/). 